\title{
The transparent failure of norms to keep up standards of belief
}

\author{
Ema Sullivan-Bissett ${ }^{1} \cdot$ Paul Noordhof $^{2}$ (iD
}

Published online: 14 February 2019

(C) The Author(s) 2019

\begin{abstract}
We argue that the most plausible characterisation of the norm of truth-it is permissible to believe that $p$ if and only if $p$ is true-is unable to explain Transparency in doxastic deliberation, a task for which it is claimed to be equipped. In addition, the failure of the norm to do this work undermines the most plausible account of how the norm guides belief formation at all. Those attracted to normativism about belief for its perceived explanatory credentials had better look elsewhere.
\end{abstract}

Keywords Belief · Norms · Transparency · Function · Standards

Some find normativism about belief - that belief is constitutively normativeantecedently plausible. For such folk, the project of interest is that of arriving at the proper description of this normativity, and answering questions such as whether there are obligations or permissions relating to what we believe, whether having true beliefs is good in itself, and so on. On the other hand, some are attracted to normativism by its explanatory credentials, for example, it might be thought able to explain why we are unable to will beliefs, or why Transparency characterises doxastic deliberation. It is this second, explanatory, support for the normative project we focus on here. In earlier work, one of us has argued that normativism

Paul Noordhof

paul.noordhof@york.ac.uk

Ema Sullivan-Bissett

e.1.sullivan-bissett@bham.ac.uk

1 Department of Philosophy, University of Birmingham, Birmingham, UK

2 Department of Philosophy, University of York, York, UK 
fails to explain why we cannot believe at will (Noordhof 2001). The prospects are just as bad for the explanation of Transparency.

Transparency is taken to characterise doxastic deliberation, that is, the conscious activity in which we are engaged when considering whether to believe that $p$. Transparency is the fact that ' $[\mathrm{t}] \mathrm{he}$ question of whether to believe that $p$ is settled by, and only by, resolving whether $p$ is true' (Shah 2003: 447). The question which frames deliberation of this kind is settled for us when we resolve whether $p$ is true, and there are no further considerations for or against believing that $p$, once we have so resolved (Shah and Velleman 2005: 499). ${ }^{1}$

Our view is that, in the case of Transparency, the two pathways to normativism are in tension. The most plausible characterisation of the normativity that attaches to belief formation via deliberation is unable to explain Transparency, in spite of the fact that it is advertised as able to do so (Shah and Velleman 2005: 500). We argue that various characterisations of this normativity which might provide explanations are implausible, and that this might be obscured by not keeping certain distinctions - between prescription, evaluation, and correctness-clear at the outset.

\section{Transparency and its explanation}

The explanatory credentials of the normative approach were touted as an important consideration in its favour in contrast to the dilemma that faced teleological accounts of belief (Shah 2003). Teleological accounts appeal to the idea of beliefs being regulated for truth by some agential aim (or sub-intentional surrogate), it is this feature of belief which secures evidence responsiveness. The dilemma they face is that if one makes the regulation sufficiently weak to accommodate the fact that beliefs can arise without being solely regulated by evidence (e.g. in cases of wishful thinking), then the question of whether to believe that $p$ does not boil down to the question of whether $p$ is true. On the other hand, if the required truth regulation is strong enough to rule out the impact of these other influences, then any putative belief that fails to be formed on the basis of sensitivity to evidence alone fails to count as a belief at all (Shah and Velleman 2005: 500). The key move of the normativist is to appeal to normative constraints on the formation of belief which may, of course, be infringed, and identify a specific kind of belief formation-doxastic deliberation-in which they have an exclusive voice (Shah and Velleman 2005: 501).

Our main point is a quick one: the only plausible characterization of the normativity connecting belief and truth is:

(N) it is permissible to believe that $p$ if and only if $p$ is true. ${ }^{2}$

\footnotetext{
${ }^{1}$ We set aside the role of pragmatic reasons in Nishi Shah and J David Velleman's framework. They claim that such reasons only have a role in attributing to acceptance the status of belief, they bear only on the classification of something as belief and do not relate to its formation in deliberation (Shah and Velleman 2005: 517-18).

${ }^{2}$ We write the permissibility of the norm in explicitly (following Whiting 2010). Shah and Velleman capture it, as you ought to believe that $p$ only if $p$ is true (where they take their norm to be permissive, not injunctive (Shah and Velleman 2005: 519)). We note problems with this formulation later (Sect. 2).
} 
This norm cannot play the envisaged role of explaining Transparency. ${ }^{3}$ Let us explain.

Suppose you have deliberated and arrived at the conclusion that not-p. The permissibility norm holds that it is impermissible ${ }^{4}$ to believe that $p$. All good so far. Now suppose you have deliberated and arrived at the conclusion that $p$. What does the permissibility norm hold in this case? It tells you that it is permissible to believe that $p$. That might be thought the right result for the normativist, we suggest that it is not.

It being permissible to believe that $p$ is a far cry from it being settled for you to believe that $p$. The norm tells you that you are permitted to believe that $p$, but that is all it tells you. It might nevertheless not be a good idea to believe that $p$, perhaps doing so would be painful, disloyal, or whatever. The permissibility norm is thus not strong enough to generate Transparency (it being settled for us whether to believe that $p$ when we conclude that $p$ ).

The normativist may well point out that one cannot fail to form the belief that $p$ upon settling that $p$. We agree that there is a question mark over this. However, this fact (if it is one) does not help the normativist, it only reveals that their position is not explanatory (as demonstrated by the no guidance objection, Sect. 6). The normativist's position does not rest on it being the case that if it is settled for you that $p$, then you cannot fail to form the belief that $p$. Their position is rather that it is the permissibility norm that explains Transparency-that is, whether to believe that $p$ is settled by whether $p$ is true. It is in this endeavour, we argue, that normativism fails.

With our main point up front in the paper's opening section, we move to distinguish our argument from those made by Asbjørn Steglich-Petersen and Conor McHugh (Sect. 2). What remains is structured around the ways in which our point might be obscured by inattention to distinctions (Sect. 3), by the thought that, within the context of deliberation, the permissibility norm does more (Sect. 4); and by the thought that, when we consider what the normativist will say about withholding belief, the permissibility norm is sufficient or implausible (Sect. 5). Finally, we turn

\footnotetext{
${ }^{3}$ It might be thought that all of the ways we might capture belief's relationship to truth in a prescriptive norm will generate an implausible norm. Take a case in which $p$ is true but you have no evidence that it is, ought or may you believe it? It seems not. Suppose that you have good evidence for $p$ but that $p$ is false. Ought, or may you believe that $p$ ? Perhaps, actually. We note then that there is more to say about the permissibility or obligation to believe particular propositions than just whether or not they are true. However, the truth norm as we have stated it has been claimed able to explain Transparency. The claim is that when in the business of doxastic deliberation we recognize the truth norm and are guided by it (or display our commitment to it, see Sect. 6). There may well be lots of things to say about the mere truth of propositions generating obligations or permissions, but the normativist position we are interested in claims that the permissive truth norm explains Transparency, and it is on these grounds (and not the grounds concerning appropriate norms more generally), that we take her on. Moreover, if evidence for $p$ just contributes towards the presentation of $p$ as true to the subject, then no amount of evidence could take the subject beyond being permitted to believe that $p$.

${ }^{4}$ We take it that if something is not permissible it is impermissible. Although S not being happy does not entail S being unhappy, something not being possible does entail that it is impossible. We take it that permissibility is more like possibility than happiness. If this is not right, so much the worse for the normativist.
} 
to the no guidance objection to normativism. The most plausible response from the normativist to the explanatory challenge raised by the no guidance objection is that the norm of truth guides our belief formation indirectly. We explain how this response is undermined by the argument that we develop here. This suggests that we have identified a key explanatory difficulty for normativism (Sect. 6).

\section{Steglich-Petersen's and McHugh's objections to normativism}

We should distinguish our argument against normativism from ones offered by Steglich-Petersen (2008) and McHugh (2013b). Steglich-Petersen is concerned with the question of whether Transparency supports Evidentialism about epistemic reasons, the thesis that only evidence can be reason for belief (Shah 2006: 482). He takes on Shah's claim that Transparency plus the deliberative constraint entails Evidentialism. The constraint as applied to belief is:

$R$ is a reason for $X$ to believe that $p$ only if $R$ is capable of disposing $X$ to believe that $p$ in the way characteristic of $R$ 's functioning as a premise in deliberation whether to believe that $p$. (Shah 2006: 487)

Steglich-Petersen asks what kind of normative force is had by conclusive evidence in being a reason for believing $p$, and considers its having the normative force of a perfect reason (a la Broome 2004), a pro tanto reason, an enticing reason, or generating mere permission to form the belief (Steglich-Petersen 2008: 543). Taking the perfect reason reading to be implausible, and the pro tanto and enticing reason readings to be incompatible with Evidentialism, Steglich-Petersen turns to the idea that the normative force had by conclusive evidence for $p$ is in generating permission or entitlement to believe that $p$.

However, understanding epistemic reasons as permissions will mean that they do not satisfy the deliberative constraint (which Shah thinks delivers Evidentialism when coupled with Transparency). This is because if epistemic reasons are merely entitlement conferring reasons, recognizing $R$ as an epistemic reason to believe that $p$ cannot by itself be the reason for which I believe that $p$ ' (Steglich-Petersen 2008: 545). There is no sound deliberative route, says Steglich-Petersen, from being entitled to believe that $p$ to believing that $p$. On the entitlement reading of epistemic reasons, they are not enough to motivate belief.

Our point is different. We are interested in the truth norm being able to explain the presence of Transparency-why our doxastic deliberation has this feature. We are not interested in motivation, specifically, the normative nature of reasons and whether a particular understanding of this normative nature-as a permission-can explain why reasons are capable of disposing a subject to believe what they support. Steglich-Petersen takes Transparency and the deliberative constraint as premises and shows that no account of the normative force of reasons entails Evidentialism. We are interested in a candidate explanation of Transparency.

There are, of course, connections between our point and Steglich-Petersen's. Suppose that only the truth norm provides the proper characterisation of the (subjective) normative force of reasons for a subject to have a belief. Suppose, 
further, that attention is switched from the success of an argument for Evidentialism to an explanation of Transparency in terms of the normative force of reasons for belief. Then a point about what is still open to a subject with a conclusive reason for $p$ (and thus permission to believe that $p$ ) will correspond to our points about what is objectively permissible as characterised by the truth norm. Even, here, it should be noted that Steglich-Petersen is interested in conclusive reasons that need not entail $p$ but make the belief that $p$ unassailable. By contrast, we are looking at the explanatory role of a norm concerning what is permitted if $p$.

We turn now to McHugh. He argues that there is a gap between accepting the prescription of the truth norm and being motivated to act in accordance with it. ${ }^{5} \mathrm{He}$ notes that the gap might be bridged by a version of motivational internalism, but argues at length that versions of motivational internalism that might help the normativist are, in fact, false. This is a mischaracterisation of the situation.

Our discussion differs from his in two ways. First, his focus is on the following formulation of the truth norm.

\section{$(\mathrm{N}-)$ Believe $p$ only if $p$ is true}

The prescription to believe $\mathrm{p}$ implicitly takes the norm to be that you ought to believe that $p$ only if $p$ is true. This formulation, which he gets from Shah, is not the considered formulation of the norm of truth endorsed by Shah and Velleman and is not equivalent to it (Shah 2003, pp. 448-449; Shah and Velleman 2005: 519). 'You ought to believe that $p^{\prime}$ is equivalent to 'it is not permissible not to believe that $p^{\prime}$. So McHugh's target formulation is 'it is not permissible not to believe that $p$ only if $\mathrm{p}$ is true'. Let $p$ be true. Then a necessary condition of it being impermissible not to believe that $p$ is met. But it has no implications about what is permissible. It is compatible with the necessary condition holding that it impermissible to believe that $p$ for some other reason, for example, that the evidence is against $p$ (on certain nonfactive views of evidence). Let $p$ be false. Then it is not the case that you ought to, or are required to, believe that $p$. However, that still leaves it open whether you are permitted to believe that $p$. $(\mathrm{N}-)$ is not equivalent to $(\mathrm{N})$ and, indeed, inadequate in ways $(\mathrm{N})$ is not. Conclusions about the success or failure of normativism are illgrounded on this formulation.

Second, and more importantly, there are no grounds for thinking that the internalist principles McHugh identifies are the problem. Internalist principles concern the appropriate connection between the norms in play and a subject's motivation as a result of acceptance of those norms. Consider the stronger internalist principle McHugh considers (int 2 , p. 454) covering withholding and, thus, closest to a norm McHugh considers would explain Transparency ${ }^{6}$ :

\footnotetext{
5 Steglich-Petersen (2006) prefigures this objection from McHugh. He argues that Transparency cannot be explained by appeal to the norm, since the motivation stemming from the norm would have to be implausibly strong (Steglich-Petersen 2006: 506-507). He does not, though, consider ways to plug the motivational gap on behalf of the normativist by various forms of motivational internalism.

6 As characterised by us, his characterisation is stronger: 'Pragmatic considerations cannot occur to a thinker, within doxastic deliberation, as relevant to what to believe' (2013b: 448). He suggests that the claim of Transparency is too strong, if it is intended to rule out that a deliberator 'cannot so much as be
} 
If $\mathrm{S}$ accepts a norm $\mathrm{N}$ of the relevant kind for act-type $\Phi$, then $\mathrm{S}$ will be deliberatively motivated to $\Phi$ or to refrain from $\Phi$ ing, if at all, only by N-directed considerations. (McHugh 2013b: 454)

The key question is whether S also accepts other norms relating to act type $\Phi$. No internalist would endorse the above principle if other norms were also in play, but it is to be assumed that they are not. So now we should consider whether it appropriately describes the link between the acceptance of norms and motivation, given that the identified norm $N$ is the only norm in play relating to act type $\Phi$. In that case, the principle seems plausible. A subject will be deliberately motivated by only N-directed considerations. That is just what it is to be deliberating and accepting $\mathrm{N}$ as the only relevant norm. Any other motivational factors would be extra-deliberative, akin to wishful thinking, or the like. Noting that there might be other considerations that come into play, where the norm does not speak, does not demonstrate that there are other deliberative motivations the principle does not cover (cf. McHugh 2013b: 454). This is not an idiosyncratic point on our part. McHugh makes clear that he recognises that pragmatic considerations may causally influence beliefs without affecting the deliberative motivations for belief (McHugh 2013b: 447, fn. 2). Our earlier discussion suggests that there are few motivational consequences of the norm in question. The key one would be that if $p$ is false, then $\mathrm{S}$ is not motivated to believe that $p$. However, the principle with its qualification 'if at all' covers this case. The problem is not with the principle but the formulation of the norm. So it is simply a mistake to characterise the situation as one in which the various internalist principles that might help are, in fact, false. They are, for all we have seen, true but no help.

To underline this point, consider our preferred formulation of the norm.

(N) It is permissible to believe that $p$ if and only if $p$ is true.

Our point is that this norm cannot explain Transparency given that, when $p$ is true, a subject is only permitted rather than mandated to believe it. The question of whether or not to believe that $p$ will always involve extra-normative considerations. Therefore, the norm cannot be the explanation of the basis of Transparency. In McHugh's terms, the internalist principle given above can be true. Subjects who accept the norm may be motivated not to believe that $p$, if not $p$, and motivated to take $p$ as something they may believe, if $p$ is true. The question of whether to believe $p$ will not be settled as a result of settling whether or not $p$.

Footnote 6 continued

struck by pragmatic considerations' (McHugh 2013b: 449), and so suggests that we move to the claim of strong exclusivity ('Pragmatic considerations cannot deliberatively motivate belief or withholding belief' (McHugh 2013b: 449)). However, Shah and Velleman do not commit to this stronger implausible Transparency, and in fact make the claim in terms of what can guide one's deliberative belief formation, what McHugh dubs strong exclusivity (see e.g. Shah and Velleman 2005, 531, n. 15; 533, n. 39). 


\section{Prescriptions, evaluations, and standards}

Normativists often start with the claim that it is correct to believe that $p$ if and only if $p$ is true (Shah and Velleman 2005: 500-502). This might suggest that, since correctness is linked up to truth, so too is doxastic deliberation. And so, of course, the question of whether to believe that $p$ will come down to the question of whether $p$ is true. However, normativists do not take appeal to correctness to be sufficient for a characterisation of a norm about truth. That is because there are standards of correctness without a normative dimension, and so they add that correctness is this context is to be understood as having normative significance (e.g. McHugh 2012b: 8).

It is up for grabs what counts as an uncontentious example of standards of correctness which are non-normative. Candidates have included chess, the filling out of Sudoku grids, and driving regulations in Saudi Arabia (ruling out women drivers) (McHugh 2012b: 8; Bykvist and Hattiangadi 2013: 103). To be clear, judging that for example, a woman who drove in Saudi Arabia would contravene local standards, is not to judge that that woman ought not to drive (Bykvist and Hattiangadi 2013: 103). We add parking regulations as well as guidelines concerning features that a well-made spanner should possess to the set of standards of correctness that are non-normative.

In some cases we have standards which many people would not endorse, and then it might be easier to see the difference between a standard being in place and there being something normative about that standard (driving regulations in Saudi Arabia being the obvious candidate from the above list). In other cases the difference between a standard being in place and there being something normative about it may be obscured by our already endorsing the standard. It is in this former sense of standard that the standard for belief characterised above (it is correct to believe that $p$ if and only if $p$ is true) is utterly uncontroversial. Beliefs meet the standards for belief-that is, are correct beliefs-if and only if they are true beliefs.

If it turned out that we endorse the standard of correctness for belief as a matter of brute psychological fact, we would have an explanation of Transparency. The question whether to believe that $p$ is settled by answering the question whether $p$ is true because we endorse the standard of belief that has it that correct beliefs are true beliefs. To endorse a standard in this sense is to adopt or have a positive attitude towards. However, this is not a normative account. What we have just sketched is rather an account which appeals to the utterly uncontroversial standard that correct beliefs are true beliefs, and adds a claim about our being motivated to believe in line with that standard. Normative accounts appeal to something more than correctness plus motivation.

The gap between standards of correctness and normativity is also brought about by the fact that some cases of belief are correct but not ones that we ought to have. Consider beliefs about the number of blades of grass of every lawn of private houses in London. There are thousands of beliefs relating to this. They will be correct if they get the number of blades right for each lawn. They are not, though, beliefs that we ought to have (see Bykvist and Hattiangadi 2007, 2013, for reasons to avoid a 
norm which entails all true beliefs are ones we ought to have). Such cases motivate normativists to have their normatively significant correctness conditions for belief understood in terms of permissibility rather than obligation as we have already observed. Shah and Velleman write:

But correctness itself is a permissive rather than injunctive notion. A norm of correctness forbids the holding of beliefs that would be incorrect, but it merely permits the holding of correct beliefs. One is not required to hold every belief that would be correct. (Shah and Velleman 2005: 519)

This makes clear that they hold the characterisation of the norm of truth to which we appealed in our argument at the outset, viz. it is permissible to believe that $p$ if and only if $p$ is true. If the proper characterisation of the norm of truth had been in terms of obligation to believe, then it is easy to see how settling that $p$ is true would be all that we need to do in order to determine whether to believe that $p$. If, however, settling that $p$ tells us that we are permitted to believe that $p$, then the question of whether to believe that $p$ remains open. Transparency is unexplained.

Is there another option for the normativist in light of this shortcoming of the norm to explain Transparency? McHugh takes the proper understanding of the norm to be evaluative rather than prescriptive (McHugh 2012b: 10). According to him, true beliefs are good, and false beliefs are bad. We will come back to whether the move to evaluation over prescription avoids the argument when we turn to withholding belief later (Sect. 5). But first, let us turn to what many may feel are more obvious lines of resistance.

\section{Within the context of deliberation}

A natural response to our argument is to appeal to the context in which the norm is at play. Specifically, whilst the norm is indeed merely permissive, it operates in a context in which we are aiming to arrive at a belief one way or another about a matter. That is, when we enter deliberation over whether to believe that $p$, we are seeking to form a belief that $p$, or a belief that not- $p$. If that is right, then once we settle that $p$ is true, the norm tells us that the only permissible option of the two we began with is to believe that $p$. And so once it is settled for us whether $p$ is true, it is also settled for us whether to believe that $p$. The norm works to single out which of the options we began with is permissible. Another, similar line of response is to say that deliberation over whether to believe that $p$ occurs in the context of inquiry. When we inquire over whether to believe that $p$, we desire the truth about a certain subject matter expressed in $p$. This desire, coupled with the permissibility norm, again makes the question of whether to believe that $p$ settled, once we settle whether $p$ is true.

These objections to our argument concede at the outset that the normativist's permissibility norm is insufficient to explain Transparency, and so appeal to an additional feature - the aims or desires of the deliberator. The first objection presents a hybrid picture, one explanatory element is the permissibility norm, but only in the context of a process with the aim of believing something. The second makes the explanatory appeal to norms redundant: if inquiry is characterised by the 
desire for truth, then that is why, on settling whether $p$ is true, there is no further question about whether to believe that $p$.

The first option then may be more attractive, since it still promises to retain explanatory power for the truth norm. However, to adopt such a hybrid picture is still to concede our point, since normativism is shown to be insufficient to explain Transparency. In addition, a further problem lurks. We have characterised deliberation as a context in which a subject is seeking to form a belief about the matter at hand. This is what made the upshot of being merely permitted to believe that $p$ but not doing so unacceptable. Nevertheless, this characterisation of deliberation allows for there to be other considerations in play to rule certain beliefs impermissible that are permitted by the norm of truth. If non-truth related rulings out on grounds of, for example, a belief being too harmful or unappealing are allowed, then the question of whether to believe that $p$ is not over once we have settled whether $p$ is true. Whether to believe that $p$ will be a function of the truth norm plus whatever considerations there are drawn from our attitudes.

Suppose the normativist makes the additional claim that deliberation is the kind of activity that only allows for one kind of ruling out, impermissibility due to falsity. The difficulty now is that there seems no explanatory role for the truth norm to play. Whatever role it might have played, is now taken over by a claim about the essential nature of deliberation.

Perhaps then, normativists will want to appeal to an additional norm relating to when it is appropriate to withhold belief rather than make any of the moves described above. We turn to this line of response next.

\section{Normativism and withholding}

The normativist might say that when we deliberate over whether to believe that $p$, what we are up to is considering the most appropriate doxastic state to be in, regarding $p$. They might add that withholding belief is a doxastic state, and so the kind of thing that can be ruled out. There are two ways of developing this response to our argument. First, if we settle that $p$, then believing that $p$ is the only permissible doxastic state to be in-withholding belief is ruled out just as believing that not-p is ruled out. This means that there can be no withholding belief that $p$ for non-epistemic reasons as we suggested in the previous section. The second way of developing the response is to say that the permissibility norm does not exhaust the norms governing doxastic states once we have captured withholding belief under that label. There are further norms governing withholdings. We will take these lines of response in turn.

\subsection{Withholding is a doxastic attitude}

The first line of response is that if we are deliberating over whether to believe that $p$, failing to form a belief is not a legitimate outcome of such deliberation, since doing so is itself to adopt an impermissible doxastic attitude. If that's right, then we cannot argue that if believing that $p$ is permissible, the question of whether to believe that 
$p$ is still open. When we settle that $p$, say, the option of withholding belief on the matter has been ruled out as an impermissible attitude and so we have settled on believing that $p$ too.

Suppose I am deliberating over whether to accept an invitation to a party. I could say yes, I could say no, or I could say maybe. But equally, I could fail to respond to the invitation, and doing so is not equivalent to saying 'no' or 'maybe'. So the claim that failing to form a belief is nevertheless to have a doxastic attitude within the remit of, and ruled out by, the permissibility norm, is in need of defence.

Perhaps the concern over our appeal to failure to form a belief is this. When one deliberates over whether to believe that $p$, one focuses on whether $p$ is true. This focus together with the permissibility norm is enough to explain Transparency. We cannot, when focused on whether $p$ is true, suddenly withdraw from arriving at a doxastic attitude with respect to $p$. We either believe that $p$, believe that not- $p$, or withhold belief on the matter. To fail to form a doxastic attitude is to stop deliberating rather than complete the deliberation and arrive at an outcome.

It is questionable whether stopping deliberating fails to be a legitimate outcome. Stopping because you are distracted may fail to count. But stopping because you have judged that the process is unproductive for some reason seems like a legitimate outcome. We proceed on the assumption that the normativist we have in mind wants to rule out even this.

What then is this doxastic state of withholding belief on the matter of $p$ that we might seem to have overlooked? One thought is that it is just being in a state of nonbelief with respect to $p$. The inadequacy of this characterisation should be obvious. As Jane Friedman points out, when we come into the world, we would not be properly described as withholding belief with respect to whether bumblebees hibernate during the winter, but we do come into the world in a state of non-belief about this matter (among others).

A better thought might be that withholding belief is being in a state of non-belief for epistemic reasons. Friedman make two points against this conception. First, the state may persist even once those epistemic reasons are defeated, and so one is no longer in the state of not believing that p for those reasons, but one is nevertheless properly described as withholding belief that $p$. Friedman gives the example of someone withholding belief on whether Martians exist. The subject's reasons for doing so are epistemic ones relating to there being no way of knowing whether Martians exist. Next the subject learns that such reasons are defeated (NASA develops-but have not yet used-technology to discover whether Martians exist). The subject's reason for not believing that Martians exist is defeated, but that does not guarantee that he will stop withholding belief about whether Martians exist (Friedman 2013: 175-176).

The second problem with understanding withholding belief as being in a state of non-belief for epistemic reasons is the fact that one can withhold belief for nonepistemic reasons. One might, for example, feel that it is morally corrupt to have any beliefs about Middle East politics (Friedman 2013: 175, 178). 
In light of the failure of these conceptions and others, ${ }^{7}$ Friedman argues that withholding belief is an attitudinal commitment to indecision (2013: 177-181). But, of note is that an essential motivation for Friedman's view is the recognition of the legitimacy of non-epistemic reasons-one can withhold belief for such reasons. But this means that while it may be permissible to believe that $p$ when it is settled for one that $p$ is true, there remains a further question as to whether to believe that $p$ rather than withhold belief. The question is not settled. Non-epistemic reasons can still proclaim that one ought not to believe.

So normativism has no explanation of Transparency even when taking into account withholding belief as a doxastic state. There is no objection to our argument to be found here.

\subsection{Withholding has evaluative status}

Let us turn then to the second idea which headed up Sect. 5: that there are further norms governing withholding belief. ${ }^{8}$ McHugh develops this idea, claiming that if you withhold over $p$, even though you have obviously conclusive and indefeasible evidence that $p$, then you are epistemically criticisable. Nevertheless, he denies that you would be mistaken in the same way as you would if you believed not- $p$ in the face of such evidence (McHugh 2012b: 16, 18).

Instead of taking the relevant norms to be prescriptive, McHugh holds them to be evaluative. His general thesis is that:

For any $S, p$ : if $\mathrm{S}$ believes that $p$, then that belief is good if $p$ is true, and that belief is bad if $p$ is false. (McHugh 2012b: 19)

Here 'good' is taken attributively as in is a good belief, where this does not imply is good generally. So his more specific thesis is:

For any $S, p$ : if $\mathrm{S}$ believes $p$, then that belief is a good doxastic attitude to have to $p$ if $p$ is true, and that belief is a bad doxastic attitude to have to $p$ if $p$ is false. (McHugh 2012b: 22)

Withholding belief when $p$ is true is neither a good nor bad attitude to have. Therefore, from McHugh's perspective, when $p$ is true withholding belief it is worse than believing $p$ and better than believing not- $p$.

\footnotetext{
${ }^{7}$ Friedman overviews some other conceptions of withholding belief, which we forego discussion of here. We note only that we find her negative claims about these other options plausible, and so opt for her positive characterisation of withholding in an effort to see if it helps the normativist.

${ }^{8}$ We read McHugh's framework here as compatible with both withholding belief as the absence of a doxastic attitude and with withholding belief as itself a doxastic attitude. McHugh is only committed to withholding belief being epistemically better or worse than forming a belief on the matter of $p$. We see no reason this evaluative scale could not be adopted by those who take withholding to be the absence of a doxastic attitude, as well as those who take it to itself be a doxastic attitude.
} 
Perhaps then the normativist can explain Transparency via an account like McHugh's. ${ }^{9}$ The idea might be that the permissibility norm, together with McHugh's evaluative scale of possible attitudes towards $p$, explains Transparency since when it is settled for you that $p$, the best attitude you can have towards $p$ is belief that $p$. Withholding would be to have a less good attitude than you could.

We see two problems with this proposal. First, McHugh's evaluative position is framed in terms of the evaluative status of the situation of $S$ believing that $p$. So the claim is not that having the belief that $p$ (when $p$ is true) is good and thus something at which to aim. Rather, it is only good if you have the belief. This is to avoid the problem of recommending belief in blindspot propositions (those which, if believed, would be false, e.g. there are no believers) (Bykvist and Hattiangadi 2007: 281). The consequence, though, is that when you deliberate over whether to believe that $p$ this evaluative scheme can play no role. Consider the following: if I am a safe cracker, then it would be good to have excellent safe-cracking skills. Nevertheless, this has absolutely no weight in determining what evening courses-say Intermediate Safe Cracking rather than Conversational French-I ought to go on, since I am not a safe cracker. So I can be told that when $p$ is true the possible doxastic states have the following evaluative order: believing that $p$ is better than withholding, which in turn is better than believing not-p. But that is neither here nor there when what I am deliberating over is whether to have the belief at all.

The second issue with importing this evaluative reading of the norm into an explanation of Transparency is that it is open for the goods to be weighed against others. Non-epistemic reasons ought still to be able to play a role. Such reasons may include the distress caused by having a certain belief, or the content of the belief being too trivial to give memory space to, and possibly clogging up our mental lives (if we had as many good as doxastic attitudes beliefs as we can). Such considerations would be ways in which true beliefs could nevertheless be bad as doxastic attitudes. Or, if you think that appraisal of doxastic attitude is limited to epistemic features, then there would also be ways in which something which is good as a doxastic attitude might fail to be good simpliciter, or perhaps even be bad. Either way, in deliberating over whether to believe that $p$, it would be prima facie appropriate to take these other goods into account however they are understood. In which case, the question of whether to believe that $p$ is not just a matter of whether $p$ is true. The normativist could of course say that deliberation is such that it does not allow focus upon these other evaluative properties of belief. But if she says that then, as we saw earlier, she just appeals to the essential nature of deliberation for her explanation of Transparency, and not to the normative features of it which were advertised as explanatory.

\footnotetext{
${ }^{9}$ Note that this is not what McHugh is up to, since he denies Transparency characterises doxastic deliberation (McHugh 2012a, 2013a, see Archer 2017 and Sullivan-Bissett 2017a for replies). But in any case this strikes us as a way the normativist might seek to go in light of our objection.
} 


\section{The no guidance objection}

Before concluding we speak to how our argument interacts with Kathrin Glüer and Asa Wikforss's $(2009,2013)$ No Guidance objection to the truth norm. It turns out our argument undermines the most plausible response to this objection which appeals to how the norm could be said to guide belief formation after all.

The No Guidance objection to the normative position is that subjects cannot be guided by the truth norm because in order to ascertain the norm's conditions of application - for example, that $p$ - they must already have formed the belief which is then said to be permitted. As norms are supposed to guide the activities they govern, a failure to do so speaks against there being such a norm (Glüer and Wikforss 2009: 41-45; 2013: 82-85). Although on the one hand this objection threatens normativism, on the other it obscures the explanatory emptiness of the position with respect to Transparency that we have been arguing for. That is because it can seem that there is no further question for the deliberator after they have established that it is permissible to believe that $p$ since, having arrived at the conditions under which this is so-settling that $p$-they already believe it. If the norm cannot guide because ascertaining its application conditions just is to form the belief said to be permitted, it might look like Transparency does not need explaining after all.

However, Shah and Velleman's response to the No Guidance objection underlines our argument. They say that a subject's disposition to take deliberating about whether to believe that $p$ simply to involve the question of whether $p$ is true constitutes being guided by the norm after all (Shah and Velleman 2005: 519-521). When we focus on whether $p$ is true in doxastic deliberation we manifest our commitment to the truth norm indirectly. ${ }^{10}$ Thus the No Guidance objection is answered because the fact that a subject is disposed to move to the application conditions for the norm reveals that she is so guided. However, we have shown that the disposition to take deliberation over whether to believe that $p$ to be transparent to whether $p$ is true, goes much further than what the most plausible characterisation of the truth norm (in terms of permissibility) would suggest. Our being disposed to focus exclusively on whether $p$ is true in doxastic deliberation cannot be explained by appeal to the norm or our commitment to it.

Instead, we say, our disposition to deliberate in a manner characterised by Transparency reflects our endorsement of the standard of correctness for beliefs interpreted non-normatively, namely, it is correct to believe that $p$ if and only if $p$ is true. The normativist's permissive norm is causally irrelevant to the presence of the disposition to which are our deliberative motivations conform. ${ }^{11}$ So just as the norm

\footnotetext{
${ }^{10}$ Glüer and Wikforss (2013: 85) specifically discuss the Shah and Velleman (2005) response to 'a worry related to [the] no guidance argument' which they overlooked in their original 2009 paper. Shah and Velleman's response looks prima facie plausible before one works through the problem we have identified.

11 The normativist account of the relationship between belief and truth was seen to have an advantage over teleological accounts because of the so-called teleologist's dilemma (Shah 2003: 461-463). The problem was thought to lie in the teleologist's capturing all belief as such under a descriptive requirement
} 
of truth fails to explain Transparency, so too does our disposition to deliberate as Transparency suggests fail to display the guidance of the norm. The character of our deliberation involves attachment of a greater weight to truth than a proper response to the permissibility norm requires (for more on this point see Noordhof 2001, 2003). The confusion has arisen because the standard the deliberator endorses in doxastic deliberation has a normative significance that the deliberator's practice extends beyond. So it seemed that this must be a matter of taking the permissibility norm with exclusive seriousness rather than the endorsement of belief's standard of correctness.

\section{Conclusion}

We have argued that the most plausible characterisation of the norm of truth in terms of permissibility is unable to explain Transparency in doxastic deliberation. We detailed several lines of resistance to our argument, and showed that each of them does not help the normativist give an explanation of Transparency by appeal to norms. Finally, we turned to the No Guidance objection and saw that the most plausible account of how the norm guides belief formation given this objection, is undermined by our argument. Normativists should feel free to seek to characterise the norms of belief formation if they find that plausible. We just insist that it is a mistake for them to shift to explanatory mode. Regarding that shift: a notion that transparently fails to explain Transparency and has guidance issues? Belief theorists should just say no.

Acknowledgements Authors are listed in reverse alphabetical order. Why not? Possessors of names towards the end of the alphabet unite (again)! We acknowledge the support of a European Research Council Consolidator Grant (Grant Agreement 616358) for funding Ema Sullivan-Bissett's research of which this project was a part. We would like to thank audiences at the University of York's Mind and Reason research group, the Transparency in Belief and Self-Knowledge workshop at the University of Oviedo, and the Epistemic Normativity workshop at the University of Luxembourg. Thanks also to Daniel Whiting and a referee for this journal for helpful comments which improved the paper.

Open Access This article is distributed under the terms of the Creative Commons Attribution 4.0 International License (http://creativecommons.org/licenses/by/4.0/), which permits unrestricted use, distribution, and reproduction in any medium, provided you give appropriate credit to the original author(s) and the source, provide a link to the Creative Commons license, and indicate if changes were made.

Footnote 11 continued

of truth regulation. As we already observed, the teleologist had to make this regulation sufficiently weak to capture self-deceptive and delusional attitudes as beliefs, but she is then in no position to explain Transparency by appeal to such regulation. It is ironic that normativism falls at the same hurdle. However, an aim account favoured by one of us according to which the sense in which belief aims at truth is the sense in which it has a derived biological function (Millikan 1995a: 177, 1995b: 243-244) does much better. It is from this (derived) proper function that beliefs have their standard of correctness (SullivanBissett 2017b). This standard is endorsed in deliberation and it is in virtue of this endorsement that Transparency can be explained (Sullivan-Bissett 2018). Deliberation involves the endorsement of a biologically based standard in the formation of belief. This endorsement, as we have seen, goes further than anything that can be rooted in plausible norms of belief. 


\section{References}

Archer, S. (2017). Defending exclusivity. Philosophy and Phenomenological Research, 94(2), 326-341.

Broome, J. (2004). Reasons. In R. J. Wallace, M. Smith, S. Scheffler, \& P. Pettit (Eds.), Reason and value: Themes from the moral philosophy of Joseph Raz (pp. 28-55). Oxford: Oxford University Press.

Bykvist, K., \& Hattiangadi, A. (2007). Does thought imply ought? Analysis, 67(4), 277-285.

Bykvist, K., \& Hattiangadi, A. (2013). Belief, truth, and blindspots. In T. Chan (Ed.), The aim of belief (pp. 100-122). Oxford: Oxford University Press.

Friedman, J. (2013). Suspended judgement. Philosophical Studies, 162, 165-181.

Glüer, K., \& Wikforss, A. (2009). Against content normativity. Mind, 118(469), 31-68.

Glüer, K., \& Wikforss, А. (2013). Against belief normativity. In T. Chan (Ed.), The aim of belief (pp. 80-99). Oxford: Oxford University Press.

McHugh, C. (2012a). Beliefs and Aims. Philosophical Studies, 160(245), 425-439.

McHugh, C. (2012b). The truth norm of belief. Pacific Philosophical Quarterly, 93, 8-30.

McHugh, C. (2013a). The illusion of exclusivity. European Journal of Philosophy, 23, 1117-1136.

McHugh, C. (2013b). Normativism and doxastic deliberation. Analytic Philosophy, 54(3), 447-465.

Millikan, R. (1995a). Explanation in biopsychology. White Queen Psychology (pp. 171-192). Cambridge: MIT.

Millikan, R. (1995b). Naturalist reflections on knowledge. White Queen Psychology (pp. 241-264). Cambridge: MIT.

Noordhof, P. (2001). Believe what you want. Proceedings of the Aristotelian Society New Series, 101, 247-265.

Noordhof, P. (2003). Self-Deception, interpretation and consciousness. Philosophy and Phenomenological Research, LXVII(1), 75-100.

Shah, N. (2003). How truth governs belief. The Philosophical Review, 112(4), 447-482.

Shah, N. (2006). A new argument for evidentialism. The Philosophical Quarterly, 225, 481-498.

Shah, N., \& Velleman, J. David. (2005). Doxastic deliberation. The Philosophical Review, 11(4), 497-534.

Steglich-Petersen, A. (2006). No norm needed: on the aim of belief. Philosophical Quarterly, 56(225), 499-516.

Steglich-Petersen, A. (2008). Does doxastic transparency support evidentialism? Dialectica, 62(4), 541-547.

Sullivan-Bissett, E. (2017a). Aims and exclusivity. European Journal of Philosophy, 25(3), 721-731.

Sullivan-Bissett, E. (2017b). Biological function and epistemic normativity. Philosophical Explorations, 20(1), 94-110.

Sullivan-Bissett, E. (2018). Explaining doxastic transparency: Aim, norm, or function? Synthese, 195(8), 3453-3476.

Whiting, D. (2010). Should I believe the truth? Dialectica, 64(2), 213-224.

Publisher's Note Springer Nature remains neutral with regard to jurisdictional claims in published maps and institutional affiliations. 